\title{
A Semiautomatic and Probabilistic Approach for Student Modeling in Ubiquitous Learning Environments
}

\author{
Rafael D. Araújo ${ }^{1}$, Taffarel Brant-Ribeiro ${ }^{1,2}$, Hiran N. M. Ferreira ${ }^{1,2}$, \\ Fabiano A. Dorça ${ }^{1}$, Renan G. Cattelan ${ }^{1}$ \\ ${ }^{1}$ Faculdade de Computação - Universidade Federal de Uberlândia \\ Uberlândia/MG, Brasil \\ ${ }^{2}$ Instituto Federal de Educação, Ciência e Tecnologia do Sul de Minas Gerais \\ Passos/MG, Brasil \\ \{rafael.araujo, fabianodor, renan\}@ufu.br, \\ \{brant.ribeiro, hiran.ferreira\}@ifsuldeminas.edu.br
}

\begin{abstract}
Ubiquitous Learning Environments (ULEs) enhance the automatic generation of Learning Objects (LOs), which increases the need of more adequate presentation strategies. To meet different needs and preferences of students, retrieval and personalization resources have been explored, adding cognitive theories to the student model. This paper presents a probabilistic proposal of the Felder and Silverman (FSLSM) model that includes a semiautomatic approach to its measurement in ULEs. Preliminary results indicate the existence of correlations between different types of interactions carried out by students and their respective learning styles.
\end{abstract}

Resumo. Ambientes Educacionais Ubíquos (AEUs) potencializam a geração automática de Objetos de Aprendizagem (OAs) que, por sua vez, necessitam de estratégias mais adequadas de apresentação. Para atender as diferentes necessidades e preferências dos estudantes, recursos de recuperação e personalização têm sido explorados, agregando teorias cognitivas ao modelo do estudante. Este artigo apresenta uma proposta probabilística do modelo de Felder e Silverman (FSLSM) que inclui uma abordagem semiautomática para sua aferição em AEUs. Resultados preliminares indicam a existência de correlações entre diferentes tipos de interações realizadas pelos estudantes e seus respectivos estilos de aprendizagem.

\section{Introduction}

The advance of computing in different areas has created increasingly dynamic systems that adapt to users' needs. Especially in the educational context, approaches aiming at improving the learning experience by using intelligent resources for content retrieving and personalization have arisen to avoid the so-called "one-size-fits-all" approach [Brusilovsky 2001], in which all students visualize the content in the same way.

Simultaneously, ubiquitous learning environments have boosted the automatic generation of Learning Objects (LOs) [Araújo et al. 2016]. In this context, it becomes essential to explore different resources to guide each student in a personalized way, given 
VII Congresso Brasileiro de Informática na Educação (CBIE 2018)

Anais do XXIX Simpósio Brasileiro de Informática na Educação (SBIE 2018)

the large amount of generated content. Besides, since people behave and learn in a different pace, individual differences should also be considered in this process. One of the possible approaches for this purpose regards the use of Learning Styles (LS).

An LS is a cognitive aspect grounded on pedagogical theories that have been studied in the context of adaptive educational systems. Some studies claim that their use in the engineering field has positive impacts on learning outcomes [Alshammari et al. 2015, El-Bishouty et al. 2014]. On the other hand, there are other studies that disagree with its efficacy [Kirschner 2017, An and Carr 2017]. However, criticism usually happens because many LS models have binary classifications and students are classified in one end, without considering uncertainties. Moreover, instruments used to manually assess LS are very extensive and tiring, which make students to answer their questions without proper attention or even be discouraged to answer them at all.

In this way, this paper presents a probabilistic approach of the Felder and Silverman Learning Styles Model (FSLSM) [Felder and Silverman 1988] with the addition of a semiautomatic technique for assessing LS in ubiquitous learning environments. In our approach, the model is initialized with values representing $50 \%$ of suitability for each LS. As students' LS are assessed, inferences about their possible learning preferences are performed and the probabilistic model is updated. Furthermore, the instrument used to manually assess the FSLSM, called Index of Learning Styles (ILS), is divided into system's login sessions throughout the semester, so that the LS estimation process becomes less tedious for students. In each login session, four questions - one of each dimension of the model - are presented to students under analysis. Students also accumulate points in a gamification module for each answered question.

The remainder of this paper is organized as follows: initially, theoretical background and related work are presented in Section 2; the research method and the proposed approach are detailed in Section 3, while obtained results are discussed in Section 4; finally, conclusions are presented in Section 5.

\section{Background and Related Work}

Mark Weiser [Weiser 1991] coined the concept of Ubiquitous Computing in the late 1980s to describe the increasingly ubiquitous integration of computing devices into people's daily lives. One of its research subareas, called Capture \& Access (C\&A), creates applications that record daily activities for future review. In educational contexts, the use of technology can help teachers and students in teaching/learning processes through automation of pedagogical tasks that can be accessed in different contextual moments, which gives rise to so-called Ubiquitous Learning Environments (ULEs).

Physical classrooms equipped with electronic devices, such as multimedia projectors, electronic whiteboards, microphones, and video cameras, produce multimedia artifacts capable of simulating experiences lived in the classroom in a non-intrusive way. [Abowd et al. 1996] proposed a four-phases design for C\&A applications: (i) preproduction, when instructors prepare the base content for the lecture; (ii) live recording, when multiple media streams are captured through those electronic devices; (iii) postproduction, when all captured streams are synchronized and stored; and, (iv) access, stage in which students access the content for future study. Additionally, a fifth phase, called extension, can also be included to allow instructors and students to enrich the material 
VII Congresso Brasileiro de Informática na Educação (CBIE 2018)

Anais do XXIX Simpósio Brasileiro de Informática na Educação (SBIE 2018)

with supplementary information [Pimentel et al. 2001]. This kind of environment is a potential producer of LOs. Besides providing support for automatic generation of educational materials, they are still capable of automatically or semiautomatically creating metadata with the power to become a source of information for content personalization and recommendation processes with respect to each student needs and preferences.

Many studies from the literature indicate that students learn differently from one another [Essalmi et al. 2015, Graf et al. 2014, Brusilovsky 2001]. Teaching strategies that take into account students' individual differences have been studied for some time, such as Learning Styles (LS) models. An LS model classifies learners according to the way they perceive and process information received in educational contexts. There are many LS models that describe different aspects on how students prefer to learn. Such models can determine how individuals interact and react in a learning environment, reflecting their real preferences [Felder and Silverman 1988]. Some studies claim that students' performance is improved if the learning environment provides adaptivity based on LS [Alshammari et al. 2015, El-Bishouty et al. 2014, Yang et al. 2013].

It is also possible to find studies that disagree on the effectiveness of LS, as in [Kirschner 2017, An and Carr 2017]. In general, criticisms are related to the classification of learners into only one LS without considering any mixed preferences or, even without considering that such preferences can actually change from one style to another over time, especially when only certain types of content are presented to students regarding those antagonistic models.

Nonetheless, the approach used in this work adopts a probabilistic alternative proposed by [Dorça et al. 2013] to indicate that an LS is not a unique choice neither a fixed one, which is based on the widely used Felder and Silverman Learning Style Model (FSLSM) [Felder and Silverman 1988]. The FSLSM classifies each student into eight different LS, which are grouped into four dimensions: Active/Reflective, Sensing/Intuitive, Visual/Verbal, and Sequential/Global. This model is based on the idea that each student has a preference (or tendency) for one of the two LS of each of the four dimensions, which represents a noteworthy characteristic of this model that allows Adaptive Educational Systems to create more detailed Student Models (SM) to provide a more accurate content personalization and adaptive experiences.

The FSLSM dimensions incorporate individual characteristics related to perception, processing, presentation and organization of the information during the learning process. The perception dimension (Sensing/Intuitive LS) classifies students according to the way they perceive the content (concrete $v s$ abstract content). The processing dimension (Active/Reflective LS) classifies students into proactive individuals or those who have a more passive posture. The input dimension (Visual/Verbal LS) indicates how students prefer to receive the content (visual $v s$ verbal). Finally, the organization dimension (Sequential/Global LS) indicates how students prefer the content to be organized.

In most cases, manual instruments are used for assessing students' LS. The Index of Learning Style (ILS) is a 44-questions questionnaire used to identify students' LS according to the FSLSM. Each of the four dimensions contains 11 questions with two alternatives each. The output consists of four values ranging from -11 to +11 that strength a preference for one side of the dimension. Although it is a statistically valida- 
VII Congresso Brasileiro de Informática na Educação (CBIE 2018)

Anais do XXIX Simpósio Brasileiro de Informática na Educação (SBIE 2018)

ted instrument [Felder and Spurlin 2005], its manual filling causes displeasure and lack of motivation, which can lead to possible imprecise answers. On the other hand, there are fully automatic approaches for detecting LS, but the results of assessed LS are often different in both methods [Ahmad et al. 2013]. Therefore, the use of a self-report instrument may be used to adjust the model for better results.

[Fasihuddin et al. 2016] developed a prototype system that includes an adaptation mechanism of LOs based on LS, according to the FSLSM. In their pilot study, results showed that content adaptation based on LS can decrease both time spent in learning and number of accessed LOs. Yet, the students' LS assessment process happens through the administration of the ILS in a single moment. [Mühlbeier and Mozzaquatro 2012] presented a system to identify students LS, called SDLS (System Detector Learning Styles), which combines different LS models found in the literature, including the FSLSM. The system still relies on a big questionnaire (50 objective questions) focused on each dimension proposed in used models.

There are also some data-based proposals for automatic LS detection. [Graf et al. 2008] have proposed a model based on behavior patterns in virtual learning environments that considers variables such as frequency of access and time spent in each type of LO. The work presented by [Sena et al. 2016] uses Hidden Markov Models (HMM) to infer students' preference for a particular LS of the FSLSM. Authors presented results with average scores around $85 \%$. However, the data was based on behavioral simulations in a virtual learning environment. While such automatic approaches are promising, we believe that the nature of the courses plays an important role as a parameter to predict students' preferences, not only LO information.

[Moser and Zumbach 2018] proposed the Learning Styles Genesis Model (LSGM) that describes a LS as a person's behavior in terms of repeated interactions with certain learning materials to handle the learning situation. Although they have included explicit and implicit aspects of educational material processing, they still rely on manual instruments (self-report) to assess students' LS (only visual and verbal LS were considered). They have not found any differences in learning outcome when matching LS and learning material for visual and verbal learners. However, they supported the idea of contextual and flexible LS. In this way, it is important to consider other factors for assessing students' LS as well as different LS dimensions and their evolution over time.

\section{Material and Methods}

The proposed approach was implemented into an ubiquitous educational platform called Classroom eXperience (CX) [Ferreira et al. 2016], which has been used for data collection in real settings. It includes social and collaborative functionalities, as well as content personalization and gamification features.

Through its use, instructors prepare their lectures, which are recorded in the classroom with the aid of computational devices such as electronic whiteboards, multimedia projectors, microphones, and video cameras. Captured lectures are made available to students via Web through an adaptive hypermedia application [Araújo et al. 2016]. Resulting LOs are automatically related to metadata information in the IEEE-LOM standard (Learning Object Metadata) [IEEE 2002].

As an LS is an information related to the learning of individuals and it can be 
VII Congresso Brasileiro de Informática na Educação (CBIE 2018)

Anais do XXIX Simpósio Brasileiro de Informática na Educação (SBIE 2018)

used as an individual preference parameter for content personalization, this work uses a probabilistic proposal to store students' LS based on the FSLSM [Dorça et al. 2013], which is shown by Equation 1.

$$
\begin{array}{r}
L S_{\text {student }}=\{(\operatorname{Pr} A, \operatorname{Pr} R),(\operatorname{Pr} S, \operatorname{Pr} I),(\operatorname{PrV} i, \operatorname{PrV} e),(\operatorname{Pr} \operatorname{Seq}, \operatorname{Pr} G) \\
\operatorname{Pr} A+\operatorname{Pr} R=1, \operatorname{Pr} S+\operatorname{Pr} I=1, \operatorname{Pr} V i+\operatorname{Pr} V e=1, \operatorname{Pr} \operatorname{Seq}+\operatorname{Pr} G=1\}
\end{array}
$$

where, $\operatorname{Pr} A$ : likelihood of preference for the Active LS; $\operatorname{Pr} R$ : likelihood of preference for the Reflective LS; $\operatorname{Pr} S$ : likelihood of preference for the Sensing LS; $\operatorname{PrI}$ : likelihood of preference for the Intuitive LS; $\operatorname{Pr} V i$ : likelihood of preference for the Visual LS; $\operatorname{PrVe}$ : likelihood of preference for the Verbal LS; PrSeq: likelihood of preference for the Sequential LS; $\operatorname{Pr} G$ : likelihood of preference for the Global LS.

Eight decimal values are stored in pairs - one pair for each dimension of the model. Each LS is a complementary value to its respective pair in the same dimension, for example: since Active LS and Reflective LS belong to the Processing dimension, the sum of the values $\operatorname{Pr} A$ and $\operatorname{Pr} R$ can not exceed 1, i.e., the values of each dimension does not exceed $100 \%$. This representation gives a probabilistic nature to LS, which means that the LS of each student is not a single choice and it is not even fixed. It means, therefore, that students tend to prefer one or more LS with a certain probability and this preference may evolve over time. Table 1 shows an example of the stored LS information for a fictitious student with the probability distribution for each dimension of the model.

\begin{tabular}{|c|c|c|c|c|c|c|c|}
\hline \multicolumn{2}{|c|}{ Processing } & \multicolumn{2}{|c|}{ Perception } & \multicolumn{2}{|c|}{ Input } & \multicolumn{2}{|c|}{ Organization } \\
\hline $\operatorname{PrA}$ & PrR & $\operatorname{PrS}$ & PrI & PrVi & PrVe & PrSeq & PrG \\
\hline 0.64 & 0.36 & 0.82 & 0.18 & 0.41 & 0.59 & 0.50 & 0.50 \\
\hline
\end{tabular}

Table 1. Example of the LS information of a fictitious student.

Moreover, each LS is initialized with a 50\% value to minimize the cold start problem, which indicates that the system does not know the students' preferences. In order to prevent students from getting tired and responding the instrument with inaccurate information, the ILS is used in a distributed way among usage sessions of the system during the semester. By enabling this feature, students enrolled in the course receive an informative text about the ILS, which is displayed only on their first login session (Figure 1(a)). Then, four questions - one from each dimension - are presented to students through a notification icon flagged with a red color in each new login session (Figure 1(b)).

The preference probability of the LS corresponding to the answered alternative is increased by $I=P / Q$, where $P$ is the initial probability of each $\mathrm{LS}$, that is $50 \%$, and $Q$ is the number of questions related to each dimension. In this way, every time students answer a question, 50/11 points $(\sim 4.55 \%)$ are added to the LS represented by the answer and its opposite LS is updated to the complementary value to reach $100 \%$ in that dimension. Still aiming to encourage students to answer the questionnaire, each answered question gives some points to the gamification module. Once answered all 44 questions, students earn a specific badge for this task.

This approach has been implemented and integrated into the CX's student model and used during a school semester by students of Computer Science and Information Systems majors. In total, 43 students enrolled in a Human-Computer Interaction (HCI) and 
VII Congresso Brasileiro de Informática na Educação (CBIE 2018)

Anais do XXIX Simpósio Brasileiro de Informática na Educação (SBIE 2018)

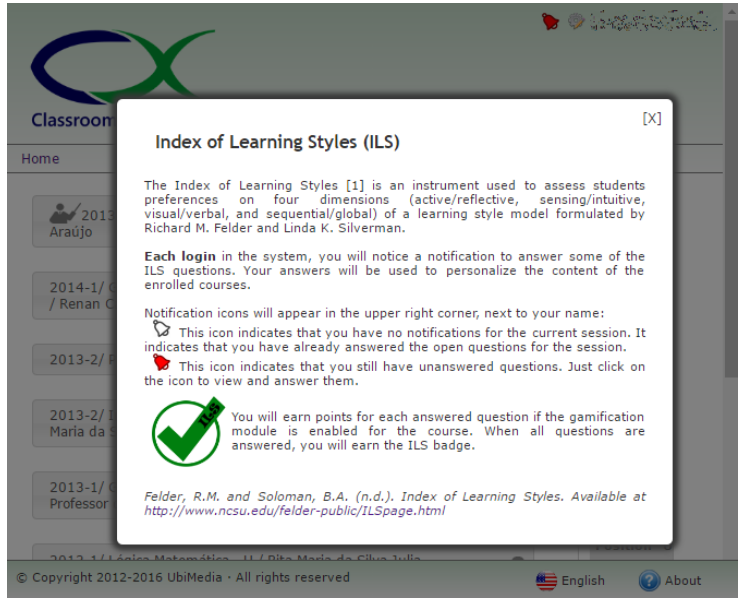

(a)

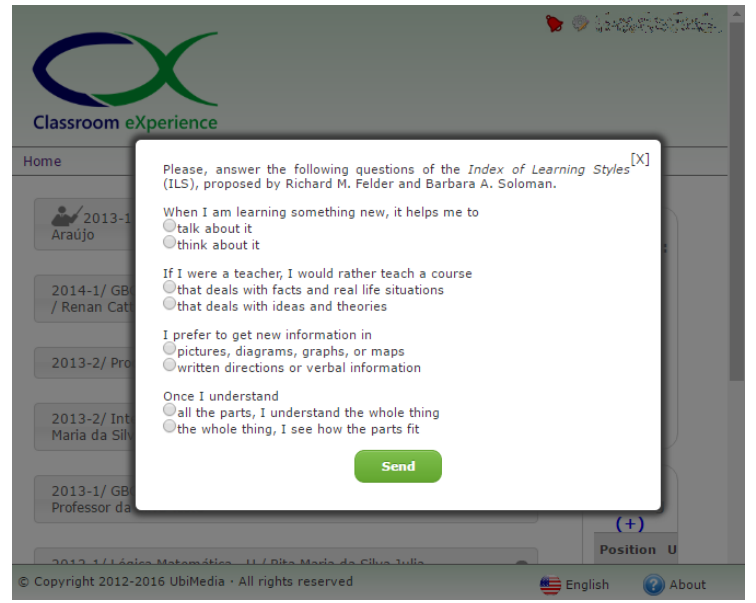

(b)

Figure 1. (a) Dialog box about the ILS; (b) Four ILS questions.

Computer Architecture and Organization (COA) courses were evaluated. For this purpose, a pretest - 10 multiple-choice questions prepared by each instructor - was initially applied to analyze students' previous knowledge in each domain.

For both the prior knowledge data and the LS information, the Shapiro-Wilk test was applied to check if samples were normally distributed. Due most of the samples presented nonnormal residuals, it was decided to check correlations between the scores obtained by students and their LS using the Spearman's rank correlation coefficient (Spearman's $\rho$ ). Then, within each sub-sample, the Spearman's rank correlation was used again in order to identify possible correlations with different interaction types carried out by students. In this study, two interaction types were analyzed: (i) quiz answering, which indicates the number of attempts to answer multiple choice questions created by instructors, and (ii) collaborative activities, which indicates the number of interactions performed in slides rating activities as well as classification of learning resource types in each slide.

The resulting correlation coefficients were analyzed according to Davis adjectives [Davis 1971], in which $r=1$ indicates a perfect correlation; $0.70<r<0.99$ represents a very high correlation; $0.50<r<0.69$ shows a substantial correlation; $0.30<r<$ 0.49 indicates a moderate correlation; $0.10<r<0.29$ shows a low correlation; and, $0.01<r<0.09$ refers to a negligible correlation. A negative correlation is related to the negative side of the ILS scale (or left-side LS) and a positive correlation is related to the positive side of the ILS scale (or right-side LS) for each dimension.

\section{Results and Discussion}

Correlation between the LS of students who participated in this study was analyzed in relation to the prior knowledge test which was carried out right at the beginning of the semester. The overall pretest median of 43 students from two courses was 2 points. Thus, two groups were created, one included students who scored less than or equal to the overall median, and the second one included students who scored higher than the overall median, as shown in Table 2.

Obtained values for the Spearman correlation coefficient indicate that students in the low prior knowledge group tended to be classified towards the Intuitive and Global 
VII Congresso Brasileiro de Informática na Educação (CBIE 2018)

Anais do XXIX Simpósio Brasileiro de Informática na Educação (SBIE 2018)

Table 2. Spearman correlation coefficients between scores obtained by students in the pretest and their respective LS.

\begin{tabular}{|c|c|c|c|c|c|}
\hline \multirow{2}{*}{ Group $^{1}$} & \multirow{2}{*}{$n$} & \multicolumn{4}{|c|}{ Learning Styles } \\
\hline & & Act/Ref & Sen/Int & Vis/Ver & Seq/Glo \\
\hline 1 & 24 & -0.242 & 0.322 & -0.083 & 0.414 \\
\hline 2 & 19 & 0.426 & -0.339 & 0.257 & -0.684 \\
\hline
\end{tabular}

LS (both with a moderate correlation) in analyzed courses. According to the FSLSM definition, these LS point out to students who prefer abstract content, including overviews, and students who learn new concepts quickly but may be careless. There was also a low correlation with the active LS, indicating a tendency to people who enjoy group working.

On the other hand, in the group of students classified with high prior knowledge about each domain, moderate correlations were found for Reflective and Sensing LS, and a substantial correlation for Sequential LS. It shows that those students prefer facts and concrete content along with a linear reasoning process, which indicates that they may be slower for acquiring knowledge, however, more carefully.

In many Computer Science-related courses, there is a trend to use a top-down approach for teaching, that is, a complex model is presented before its details in order to show its final goals. It is possible to imagine, for example, in a COA course, in which a high-level architectural diagram can represent an abstract content and, as each component is specialized and explained, one arrives at a more concrete and tangible content. In this way, it makes sense to imagine that the Intuitive and Global LS walk together for students in the low prior knowledge group. On the other hand, with a high prior knowledge, in which details and concrete facts about the content are already known, the correlations indicate another direction, that is, Sensing, Reflective, and Sequential LS.

After analyzing the prior knowledge, we tried to understand the interaction types in each of these groups, separated by course. Table 3 shows the correlations results obtained for each group. Moderate and substantial correlations were found in both sub-samples of the two courses. The most expressive result is related to the HCI course, in which all correlations for the Vis/Ver dimension pointed out to the Visual LS, including a very high correlation in the high prior knowledge group regarding the number of answered quizzes. We believe that this result is related to the nature of the HCI course, since it contemplates a lot of visual elements of software interface.

The COA course presented another interesting result. The low prior knowledge group showed a tendency to the Active LS for both interaction types, while the high prior knowledge group presented an opposite tendency, pointing out to the Reflective LS. It may be a clue indicating that students who do not know the subject seek to work in groups to build their knowledge, using quizzes as a verification of it, whereas students who already knows the subject have more confidence to classify the content according to its relevance.

These results could be used to design more personalized courses based on courses' characteristics and a student model that considers LS, taking advantage of ULEs. As an example, imagine a lecture for teaching repetition structures in a Computer Programming 
VII Congresso Brasileiro de Informática na Educação (CBIE 2018)

Anais do XXIX Simpósio Brasileiro de Informática na Educação (SBIE 2018)

Table 3. Spearman correlation coefficients between types of interaction and students' LS in low and high prior knowledge groups.

\begin{tabular}{|c|c|c|c|c|c|c|}
\hline Group $^{1}$ & $n$ & Interaction & Act/Ref & Sen/Int & Vis/Ver & Seq/Glo \\
\hline \multirow{2}{*}{$\downarrow(\mathrm{C})$} & \multirow{2}{*}{15} & Quiz answering & -0.434 & -0.157 & -0.516 & -0.165 \\
\hline & & Collaborative activities & -0.147 & -0.321 & 0.019 & -0.189 \\
\hline \multirow{2}{*}{$\uparrow(\mathrm{C})$} & & Quiz answering & 0.211 & -0.456 & -0.210 & -0.208 \\
\hline & & Collabor & 0.522 & 0.090 & 0.157 & 0.165 \\
\hline \multirow{2}{*}{$\downarrow(\mathrm{H})$} & & Quiz an & 0.151 & -0.490 & -0.354 & -0.440 \\
\hline & & Collaborative activities & 0.238 & 0.244 & -0.054 & -0.141 \\
\hline \multirow{2}{*}{$\uparrow(\mathrm{H})$} & \multirow{2}{*}{10} & Quiz ans & -0.229 & 0.458 & -0.768 & -0.381 \\
\hline & & Collaborative activities & -0.262 & 0.182 & -0.561 & -0.572 \\
\hline
\end{tabular}

${ }^{1} \downarrow:$ Students who scored less than or equal to the overall median in the pretest; $\uparrow:$ Students who scored more than the overall median in the pretest; (C) COA course; (H) HCI course; $n$ : Sample size.

course which has three subjects prepared in the following order: "For Loops", "While Loops", and "Do While Loops", as shown by Figure 2(a). Image a specific student who has tendencies for Sensing and Visual LS, it would be more suitable to rearrange such lecture to show LOs that fit his/her preference in the first place, as shown by Figure 2(a).

\begin{tabular}{|c|c|c|c|c|c|c|c|c|c|c|}
\hline Title & Agenda & $\begin{array}{c}\text { Textual } \\
\text { definition }\end{array}$ & Diagram & Example & $\begin{array}{c}\text { Textual } \\
\text { definition }\end{array}$ & Example & $\begin{array}{c}\text { Textual } \\
\text { definition }\end{array}$ & Example & Summary & $\begin{array}{l}\text { Extra } \\
\text { readings }\end{array}$ \\
\hline \multicolumn{2}{|c|}{ Introductory content } & \multicolumn{3}{|c|}{ For Loops (Subj. 1) } & \multicolumn{2}{|c|}{ While Loops (Subj. 2) } & \multicolumn{2}{|c|}{ Do While Loops (Subj. 3) } & \multicolumn{2}{|c|}{ Concluding content } \\
\hline Title & Agenda & Example & Diagram & $\begin{array}{c}\text { Textual } \\
\text { definition }\end{array}$ & Example & $\begin{array}{c}\text { Textual } \\
\text { definition }\end{array}$ & Example & $\begin{array}{c}\text { Textual } \\
\text { definition }\end{array}$ & Summary & $\begin{array}{l}\text { Extra } \\
\text { readings }\end{array}$ \\
\hline Introdu & / content & & $\overbrace{\text { Loops (Su }}^{\mathrm{s}^{2}}$ & & While LC & os (Subj. 2) & Do While & ops (Subj. 3) & & content \\
\hline
\end{tabular}

Figure 2. Example of a personalized lecture for teaching repetition structures.

These findings partially corroborate other studies of the literature regarding positive impacts of LS. However, they also raise a flag about possible misinterpretations in which learning styles do not change, or are equally used in different courses.

\section{Conclusion}

The fact that people behave and learn in a different pace requires individual differences to be properly considered in the teaching/learning process. Among several cognitive theories that could be used for this purpose, a promising one is using students' LS. Several studies indicate that the use of LS has positive impacts on learning outcomes.

This paper presented an approach for assessing students LS in ULEs according to a probabilistic proposal of the FSLSM. Considering there is controversy regarding the effectiveness of LS, mainly because some of the existing models do not consider uncertainties and classify students exclusively in one category, our model is capable of dealing with uncertainties to consider possible preferences for two competing categories.

Results showed that groups of students with low prior knowledge in the tested courses have a moderate correlation with Intuitive and Global LS, which may be related to the nature of the courses. Students in the high prior knowledge group presented 
VII Congresso Brasileiro de Informática na Educação (CBIE 2018)

Anais do XXIX Simpósio Brasileiro de Informática na Educação (SBIE 2018)

correlations with LS in opposite directions, that is, Reflective (moderate correlation) and Sequential (substantial correlation) LS. In addition, the types of interaction with the system in each of these groups may also indicate different preferences for each course. So, it would be interesting to run experiments in other areas than Computer Science, such as Literature or History, and approaches based on interaction patterns in online environments could provide a refinement of the SM. Also, results do not indicate that LS are related only to the expertise parameter, but this information can be used to make model initialization adjustments in future work.

\section{Acknowledgment}

The authors acknowledge the support of CNPq, FAPEMIG, FACOM/PROPP/UFU, IFSULDEMINAS, and PET/MEC/SESu. This study was financed in part by the Coordenação de Aperfeiçoamento de Pessoal de Nível Superior - Brasil (CAPES) - Finance Code 001.

\section{References}

Abowd, G. D., Atkeson, C. G., Feinstein, A., Hmelo, C., Kooper, R., Long, S., Sawhney, N., and Tani, M. (1996). Teaching and Learning as Multimedia Authoring: The Classroom 2000 Project. In Proc. of the 4th ACM International Conf. on Multimedia, MULTIMEDIA'96, pages 187-198,

Ahmad, N., Tasir, Z., Kasim, J., and Sahat, H. (2013). Automatic detection of learning styles in learning management systems by using literature-based method. Procedia Social and Behavioral Sciences, 103:181-189.

Alshammari, M., Anane, R., and Hendley, R. J. (2015). The impact of learning style adaptivity in teaching computer security. In Proc. of the 2015 ACM Conf. on Innovation and Technology in Computer Science Education, ITiCSE'15, pages 135-140.

An, D. and Carr, M. (2017). Learning styles theory fails to explain learning and achievement: Recommendations for alternative approaches. Personality and Individual Differences, 116:410-416.

Araújo, R. D., Brant-Ribeiro, T., Ferreira, H. N. M., Dorça, F. A., and Cattelan, R. G. (2016). Segmentação Colaborativa de Objetos de Aprendizagem Utilizando Bookmarks em Ambientes Educacionais Ubíquos. In Proc. of the 27th SBIE, 2016, pages 1205-1214.

Brusilovsky, P. (2001). Adaptive hypermedia. User Modeling and User-Adapted Interaction, 11(1):87-110.

Davis, J. A. (1971). Elementary survey analysis. Englewood Cliffs, NJ, Hentice Hall.

Dorça, F. A., Lima, L. V., Fernandes, M. A., and Lopes, C. R. (2013). Comparing strategies for modeling students learning styles through reinforcement learning in adaptive and intelligent educational systems: An experimental analysis. Expert Systems with Applications, 40(6):2092-2101.

El-Bishouty, M. M., Chang, T.-W., Graf, S., Kinshuk, and Chen, N.-S. (2014). Smart e-course recommender based on learning styles. Journal of Computers in Education, 1(1):99-111. 
VII Congresso Brasileiro de Informática na Educação (CBIE 2018)

Anais do XXIX Simpósio Brasileiro de Informática na Educação (SBIE 2018)

Essalmi, F., Ayed, L. J. B., Jemni, M., Graf, S., and Kinshuk (2015). Generalized metrics for the analysis of e-learning personalization strategies. Computers in Human Behavior, 48:310-322.

Fasihuddin, H., Skinner, G., and Athauda, R. (2016). Using learning styles as a basis for creating adaptive open learning environments: an evaluation. International Journal of Learning Technology, 11(3):198-217.

Felder, R. M. and Silverman, L. K. (1988). Learning and Teaching Styles in Engineering Education. Journal of Engineering Education, 78(7):674-681.

Felder, R. M. and Spurlin, J. (2005). Applications, reliability and validity of the index of learning styles. International Journal of Engineering Education, 21(1):103-112.

Ferreira, H. N. M., Brant-Ribeiro, T., Araújo, R. D., Dorça, F. A., and Cattelan, R. G. (2016). An automatic and dynamic student modeling approach for adaptive and intelligent educational systems using ontologies and bayesian networks. In 2016 IEEE 28th International Conf. on Tools with Artificial Intelligence (ICTAI), pages 738-745.

Graf, S., Chang, T. W., Kersebaum, A., Rath, T., and Kurcz, J. (2014). Investigating the effectiveness of an advanced adaptive mechanism for considering learning styles in learning management systems. In Proc. of the IEEE 14th International Conf. on Advanced Learning Technologies, pages 112-116.

Graf, S., Kinshuk, and Liu, T.-C. (2008). Identifying learning styles in learning management systems by using indications from students' behaviour. In Proc. of the 2008 Eighth IEEE International Conf. on Advanced Learning Technologies, pages 482-486.

IEEE (2002). LTSC 1484.12.1, Draft Standard for Learning Object Metadata. Learning Technology Standards Committee of the IEEE.

Kirschner, P. A. (2017). Stop propagating the learning styles myth. Computers \& Education, 106:166-171.

Moser, S. and Zumbach, J. (2018). Exploring the development and impact of learning styles: An empirical investigation based on explicit and implicit measures. Computers \& Education, 125:146-157.

Mühlbeier, A. and Mozzaquatro, P. (2012). Estilos e estratégias de aprendizagem personalizadas a alunos das modalidades presenciais e a distância. Revista Brasileira de Informática na Educação, 20(1):132-139.

Pimentel, M. d. G., Ishiguro, Y., Kerimbaev, B., Abowd, G. D., and Guzdial, M. (2001). Supporting Educational Activities through Dynamic Web Interfaces. Interacting with Computers, Special Issue on Interacting with the Active Web, 13(3):353-374.

Sena, E., Vivas, A., Assis, L., and Pitangui, C. (2016). Proposta de uma abordagem computacional para detecção automática de estilos de aprendizagem utilizando modelos ocultos de Markov e FSLSM. In Proc. of the 27th SBIE, 2016, pages 1126-1135.

Weiser, M. (1991). The Computer for the 21st Century. Scientific American, 265(3):6675.

Yang, T.-C., Hwang, G.-J., and Yang, S. J.-H. (2013). Development of an Adaptive Learning System with Multiple Perspectives based on Students' Learning Styles and Cognitive Styles. Educational Technology \& Society, 16(4):185-200. 